\section{Emergência e institucionalização da sexologia em Portugal: processos, atores e especificidades}

\author{
The emergence and institutionalization of sexology \\ in Portugal: processes, actors, and specificities
}

\section{Emergencia e institucionalización de la sexología en Portugal: procesos, actores y especificidades}

Violeta Alarcão 1,2

Fernando Luís Machado ${ }^{3}$ Alain Giami 2

\title{
Resumo
}

Com base na teoria dos campos de Bourdieu, este artigo analisa a emergência e a institucionalização da sexologia enquanto ciência e profissão em Portugal, identificando instituições, atores e práticas profissionais, $e$ discutindo as suas relações e especificidades. Começa por contextualizar o surgimento da sexologia moderna ocidental para uma compreensão do caso português no contexto sexológico internacional. Numa segunda parte, descreve os fatores de natureza social, cultural e institucional que têm impulsionado a profissionalização da sexologia. Na terceira, descreve a emergência da sexologia portuguesa e os seus principais marcos históricos, instituições e atores em jogo. Por fim, discute algumas implicações desse processo para o papel da sexologia como ciência e profissão. Esta pesquisa revela as dinâmicas entre processos nacionais e internacionais no campo, na transição de uma perspectiva holística da sexologia para a hegemonia da medicina sexual, e clarifica os seus mecanismos de legitimação como ciência transdisciplinar da sexualidade, sugerindo perspectivas futuras.

\footnotetext{
${ }_{1}$ Faculdade de Medicina Universidade de Lisboa, Lisboa, Portugal.

2 Centre de Recherche en Épidémiologie et Santé des Populations - Inserm U1018, Le Kremlin-Bicêtre, France.

${ }^{3}$ Centro de Investigação e Estudos de Sociologia, Instituto Universitário de Lisboa, Lisboa, Portugal.
}

\author{
Correspondência \\ V. Alarcão \\ Instituto de Medicina \\ Preventiva e Saúde Pública, \\ Faculdade de Medicina \\ Universidade de Lisboa. \\ Av. Prof. Egas Moniz, Lisboa- \\ 1649-028, Portugal. \\ violeta.alarcao@gmail.com
}

Sexologia; Domínios Científicos; Saúde Sexual e Reprodutiva;

Serviços de Saúde Reprodutiva 


\section{Introdução}

Em 1976, com a publicação da obra precursora de Foucault, História da Sexualidade 1, deu-se início a uma produção científica que coloca o problema das relações entre medicina e sexualidade sob o ângulo da "medicalização" e da "apropriação médica” 2,3,4,5.

Parte do atual controle da sexualidade pela medicina é feita pelos sexólogos 6 . Nos trabalhos pioneiros de Béjin 7,8, o poder científico dos sexólogos contemporâneos é explicado pela obtenção de um consenso perante uma definição empírica relativamente precisa de "saúde sexual”. Essa definição assenta na capacidade de obtenção de prazer e legitima os sexólogos como os peritos no "mercado das terapias", com várias abordagens terapêuticas e técnicas possíveis de obtenção de prazer.

A discussão do processo de "medicalização da sexualidade" é fundamental para contextualizar a emergência e constituição do campo da sexologia e a atividade profissional do sexólogo. Como tal, esta investigação teve como problemática de enquadramento a "medicalização da sexualidade", que inclui, numa abordagem ao mesmo tempo estrutural e dinâmica, a questão dos saberes, das organizações sociais, da organização das profissões e dos atores implicados, bem como das subjetividades. Esse conjunto compõe o que Foucault chamou de "dispositivo da sexualidade" 1.

A escolha do termo "sexologia" justifica-se porque se trata de uma designação tradicional de modos de conhecimento e intervenção no âmbito da sexualidade, por oposição aos termos "sexualidade humana”, "saúde sexual”, ou "medicina sexual”. Esses termos são mais atuais, mas conotam uma posição e um determinado grupo no conjunto de relações e conflitos que marcam esse campo. A noção de sexologia abarca assim questões amplas, como as doenças sexualmente transmissíveis, a saúde reprodutiva, o abuso sexual, além do tratamento clínico de distúrbios relacionados com a sexualidade.

Nos últimos 25 anos, aproximadamente, a profissionalização da sexologia enquanto ciência e dos sexólogos em Portugal evoluiu positivamente. Além da criação de sociedades profissionais e consultas de sexologia, deu-se o desenvolvimento do ensino, a diversificação das práticas e a divulgação de várias atividades profissionais tanto no nível nacional como internacional. Por outro lado, a sexologia portuguesa internacionalizou-se e passou a fazer parte ativa da sexologia internacional. Buscamos, assim, perceber como é que as alterações dos contextos e normas sociais que enquadram a sexualidade, por um lado, e a crescente medicalização da sexualidade, por outro, influenciaram os contornos da autonomização do campo da sexologia em Portugal enquanto campo de saber e pesquisa e as especificidades do seu processo de institucionalização, nomeadamente as dinâmicas e práticas profissionais.

Inicialmente é feita uma introdução ao surgimento da sexologia em nível internacional, para uma compreensão da sexologia portuguesa no contexto mais amplo do cenário internacional. Em seguida, descrevem-se os fatores de natureza social, cultural e institucional que têm impulsionado a profissionalização da sexologia, à luz da realidade portuguesa. Na terceira parte, descreve-se a emergência da sexologia portuguesa, os principais marcos históricos, as instituições e os atores em jogo e a forma como estes influenciam o campo. Por fim, discutem-se algumas implicações que decorrem dessa evolução profissional para o papel da sexologia como ciência e profissão. Ao longo do texto a realidade brasileira é tida como referência comparativa.

\section{Foco e metodologia}

O presente artigo baseia-se no pressuposto que as variações nas práticas profissionais da sexologia estão associadas a contextos nacionais e culturais, à formação, à organização dos serviços de saúde, e à motivação profissional 9 .

A abordagem da sexologia à luz da teoria geral dos campos de Pierre Bourdieu facilita a compreensão das dinâmicas, conflitos e consensos na origem da sua constituição e da sua consolidação. Segundo Bourdieu 10, o campo é uma esfera da vida social que se autonomiza progressivamente através da história em torno de relações sociais, enjeux e recursos específicos. O campo da sexologia é assim analisado como um "espaço estruturado de posições e tomadas de posição", onde indivíduos e instituições competem pelo monopólio sobre a autoridade científica acerca da sexualidade. Esse olhar implica traçar uma "topologia da estrutura interna do campo", de modo a desvendar a estruturação das relações de domínio e subordinação, distância e proximidade, complementaridade e antagonismo que, em determinado momento, envolvem os agentes e as instituições na luta pela legitimidade.

A análise do processo de emergência e institucionalização da sexologia em Portugal será feita à luz das transformações ocorridas na sociedade portuguesa nas últimas décadas. Como emergiu, como se estruturou, e que modificações tem sofrido o campo da sexologia em Portugal? Qual o contexto de formação da sexologia em 
Portugal e que atores profissionais, identidades e modalidades de prática refletem as evoluções e mudanças da sociedade? Quais as relações de força e os conflitos associados a esse processo?

Para responder a essas questões, e tendo por base a metodologia do estudo do campo da sexologia contemporânea no Brasil 11, foi feito um levantamento de sítios institucionais ou pessoais na Internet usando o sítio de buscas Google, com os descritores "sexologia", "sexólogo", "sexologista”, "sexualidade humana”, "medicina sexual", "terapia sexual”, "terapeuta sexual", "educação sexual" e "educador sexual". A pesquisa, realizada entre novembro de 2011 e abril de 2012, resultou num conjunto heterogêneo de atores, formado por organizações não governamentais (ONGs), sociedades científicas, clínicas, núcleos em universidades, cursos, publicações e eventos. Concretamente, por meio do sítio da Associação para o Planeamento da Família (APF; http://www.apf.pt) foi possível obter dados da constituição do planejamento familiar e da educação sexual; no da Associação Portuguesa de Andrologia (APA), dados da constituição da andrologia; e por intermédio do sítio da Sociedade Portuguesa de Sexologia Clínica (SPSC; http://www.spsc.pt), dados sobre cursos, eventos, publicações e programas de televisão e rádio, e uma lista dos serviços públicos e privados de consultas de sexologia e terapia sexual. Foi feita uma análise documental de conteúdo e a informação sintetizada em quadros.

\section{O cenário sexológico internacional}

A primeira sexologia contemporânea centra a sua preocupação nas ameaças a uma sexualidade dita normal, isto é, a sexualidade reprodutiva. Das doenças venéreas, o grande medo do século XIX, passa-se às perversões, ou seja, práticas sexuais não reprodutivas (masturbação, homossexualidade, bestialidade e "heterossexualidade" sem intenção de reprodução) 12 . A passagem do século XIX ao século XX marca uma mudança na abordagem da sexualidade, sendo por meio do discurso médico e sob uma racionalidade biológico/científica, por oposição ao discurso legal ou religioso, que passam a ser explicadas as sexualidades periféricas ao casal e à família 13. A sexologia brasileira constitui um caso interessante em que o surgimento de novos discursos especializados sobre a sífilis e outras doenças venéreas, ao longo das décadas de 1930 e 1940, fez-se justamente no âmbito mais amplo de uma reflexão sexológica. A luta antivenérea foi no sentido de um investimento cada vez maior num autocontrole por parte dos homens e de uma responsabilização dos sexualmente indisciplinados 14 .

\section{Berlim: o berço}

Em 1906, Iwan Bloch tornou-se conhecido como o pai da sexologia ao atribuir o termo Sexualwissenschaft ao estudo teórico-científico da sexualidade, ao mesmo tempo em que Berlim (Alemanha) passou a berço da sexologia e centro de produção e difusão de conhecimento 4,5 . Durante as primeiras duas décadas do século $\mathrm{XX}$, surgiram revistas, sociedades e encontros científicos dedicados à sexologia, sendo lançadas as sementes da sexologia enquanto ciência (Tabela 1).

Durante o período do nazismo, os sexólogos alemães foram perseguidos e a sexologia europeia, em geral, foi afetada pela Segunda Guerra Mundial 4,5.

\section{Estados Unidos: o renascimento}

Após a Segunda Guerra Mundial, ocorreu um renascimento da sexologia nos Estados Unidos pelas mãos de Alfred Kinsey. Por meio das suas duas grandes pesquisas (Tabela 1), Kinsey e colaboradores contribuem para a investigação nãomédica da sexualidade. Assistiu-se, nesta segunda sexologia, a um duplo descentramento: uma mudança geográfica e a transformação do objeto de atenção, que passa das "perversões" para a sexualidade "normal" 5.

Decorreram nessa fase movimentos e iniciativas institucionais de legitimação da sexologia. Nos Estados Unidos, em particular, surgiram várias revistas e sociedades científicas dedicadas à sexologia 13. Esses movimentos e iniciativas internacionais contribuíram para o processo de globalização da sexologia 9 .

\section{Globalização da medicalização da sexualidade}

Nos anos 1980, assistiu-se a uma reorientação medicalizante da impotência 15 , com um aumento de investigações e publicações sobre a disfunção erétil e o seu tratamento, tendência que se intensificou entre 1990 e 2000. É assim menorizada a terapia de casal e o tratamento psicológico, pilares do modelo de Masters e Johnson. Como refere Russo 5 , a medicina sexual fez várias rupturas em relação a esse modelo: da sexualidade feminina (dominada pela ginecologia) para a masculina (dominada pela urologia); do orgasmo para a ereção; de uma concepção relacional/psicológica para uma estritamente orgânica e genital. 
Tabela 1

Sexologia no mundo, em Portugal e contexto sociopolítico e cultural.

\begin{tabular}{|c|c|c|c|}
\hline Data & Sexologia no mundo & Sexologia em Portugal & Contexto sociopolítico e cultural \\
\hline 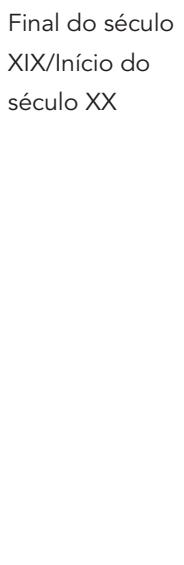 & $\begin{array}{l}\text { Magnus Hirschfeld, Havelock Ellis, Albert } \\
\text { Moll, Kraaft Ebing: "primeira sexologia"; } \\
\text { Jornal de Sexologia, em 1908; } \\
\text { Fundação da Sociedade Médica de } \\
\text { Sexologia e Eugenia, em 1913, em } \\
\text { Berlim (Alemanha); } \\
\text { Fundação do Instituto de Sexologia, em } \\
\text { 1919, em Berlim; } \\
\text { 1o Congresso de Sexologia, em Berlim, } \\
\text { em 1921; } \\
\text { Jornal de Andrologia, em 1932, e Boletim } \\
\text { de Educação Sexual, em 1933, no Brasil; } \\
\text { Fundação do Círculo Brasileiro de } \\
\text { Educação Sexual, em 1933, no Brasil. }\end{array}$ & $\begin{array}{l}\text { Egas Moniz (1874-1955) publica A Vida } \\
\text { Sexual (Fisiologia e Patologia), em } 1913 .\end{array}$ & $\begin{array}{l}\text { * Nazismo e o fim da pesquisa sobre } \\
\text { sexologia na Alemanha. }\end{array}$ \\
\hline 1940-1949 & $\begin{array}{c}\text { Fundação do Instituto Kinsey, em } \\
\text { 1947, nos Estados Unidos; } \\
\text { Alfred Kinsey publica, nos Estados Unidos, } \\
\text { Sexual Behavior in the Human Male, em } \\
1948 .\end{array}$ & & $\begin{array}{l}\text { * Constituição do crime de contágio } \\
\text { venéreo, em 1940, no Brasil; } \\
\text { * Revogação da regulamentação do } \\
\text { meretrício em 1946, na França. }\end{array}$ \\
\hline 1950-1959 & $\begin{array}{l}\text { Fundação da International Planned } \\
\text { Parenthood Federation, em 1952; Alfred } \\
\text { Kinsey publica Sexual Behavior in the } \\
\text { Human Female, em } 1953 .\end{array}$ & & \\
\hline 1960-1969 & $\begin{array}{c}\text { Criação do Clube da Placenta, no Brasil, } \\
\text { em 1965; William Masters e Virginia } \\
\text { Johnson publicam, nos Estados Unidos, } \\
\text { Human Sexual Response, em 1966; } \\
\text { Formação em sexologia na Bélgica desde } \\
\text { os anos 1960, pela Universidade Católica } \\
\text { de Louvain - programa de mestrado e } \\
\text { doutoramento. }\end{array}$ & $\begin{array}{l}\text { "Carta a uma Jovem Portuguesa" na Via } \\
\text { Latina, jornal universitário de Coimbra, em } \\
\text { 1961: lança o debate sobre a condição } \\
\text { feminina; Criação da APF, em } 1967 \text { - } \\
\text { ginecologistas Albino Aroso, Manuel } \\
\text { Neves e Castro, Purificação Araújo; } \\
\text { Criação da Unidade de Andrologia, no } \\
\text { Serviço de Urologia do Hospital de Santo } \\
\text { António, no Porto, em 1968; Criação da } \\
\text { 1ạ consulta de planejamento familiar no } \\
\text { Hospital de Santo António, no Porto, em } \\
\text { 1969. }\end{array}$ & $\begin{array}{l}\text { * Comercialização da pílula anticoncecional } \\
\text { nos Estados Unidos, em 1960: } \\
\text { possibilidade de controle da reprodução } \\
\text { pelas mulheres; } \\
\text { ** A pílula começa a ser prescrita em } \\
\text { Portugal, mas com fins estritamente } \\
\text { terapêuticos, em 1962; } \\
\text { ** Código Civil Português, 1967: a família } \\
\text { é chefiada pelo marido, a quem compete } \\
\text { decidir em relação à vida conjugal comum } \\
\text { e aos filhos; } \\
\text { * Revolta de Stonewall, em 1969: marco } \\
\text { do início do movimento homossexual nos } \\
\text { Estados Unidos. }\end{array}$ \\
\hline
\end{tabular}

(continua)

A terceira "onda" da sexologia 5 teve o seu início simbólico em 1998 com o lançamento do Viagra, marcando uma nova transformação no campo, trazendo a farmacologia para o centro das terapêuticas sexuais e tornando o andrologista/urologista o ator principal.

\section{Nascimento e desenvolvimento do campo da sexologia em Portugal}

Sem buscar traçar uma história exaustiva do nascimento e desenvolvimento da sexologia em Portugal, importa identificar os principais acontecimentos e figuras que marcaram a emergência da ciência da sexualidade e a sua constituição como campo autônomo de saber (Tabela 1). 


\begin{tabular}{|c|c|c|c|}
\hline Data & Sexologia no mundo & Sexologia em Portugal & Contexto sociopolítico e cultural \\
\hline 1970-1979 & 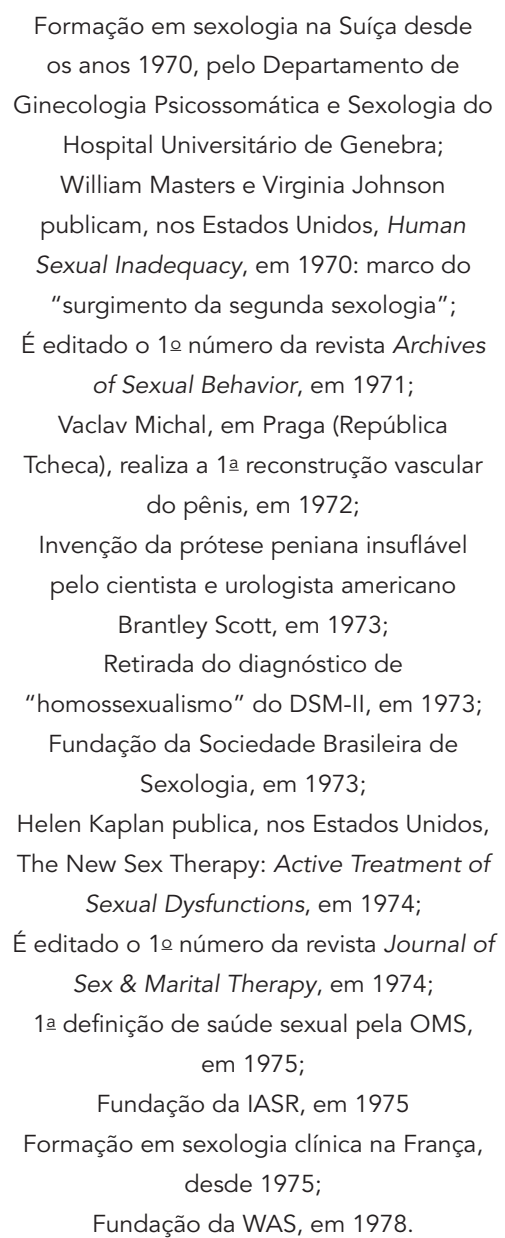 & 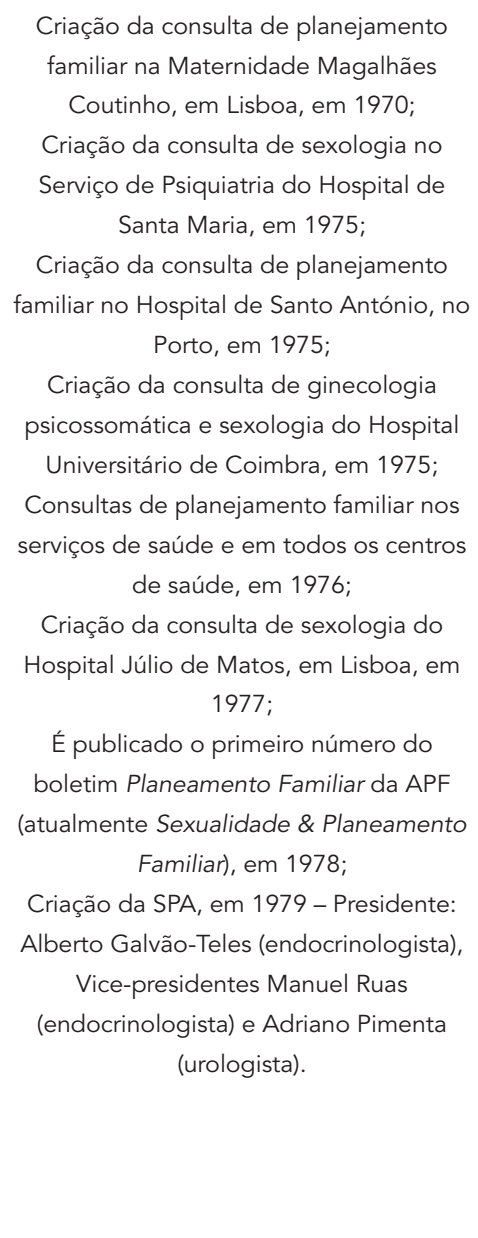 & 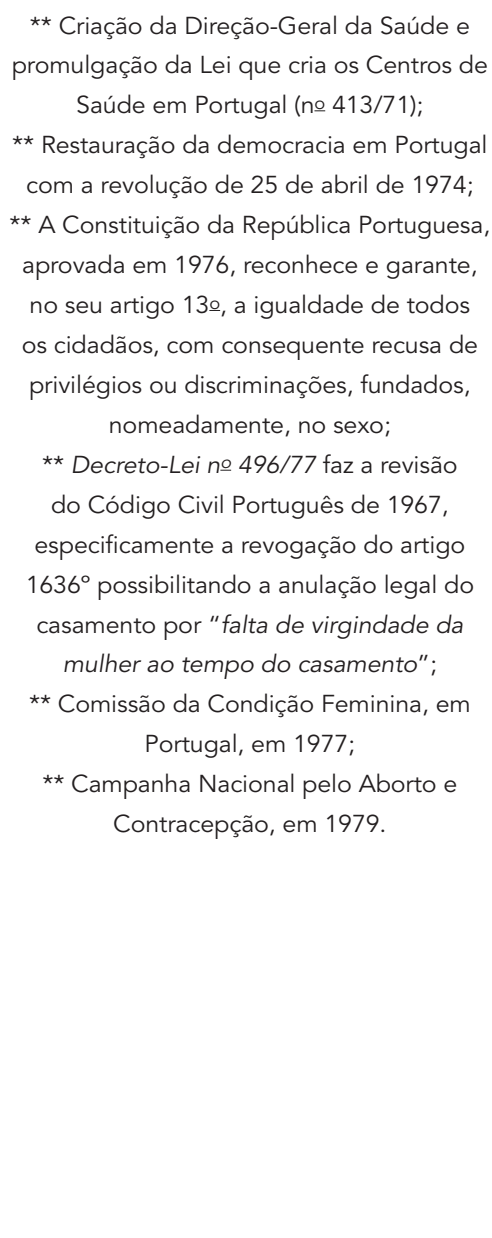 \\
\hline
\end{tabular}

(continua)

No início do século XX, os médicos portugueses, à semelhança dos seus congêneres europeus, buscavam uma articulação dos paradigmas da degenerescência, do darwinismo social e da psicanálise 16. Egas Moniz (1874-1955), ganhador do Prêmio Nobel em 1949 pela descoberta da relevância da leucotomia (lobotomia) pré-frontal no tratamento de certas doenças mentais, foi autor de uma vasta e polêmica obra científica. A sua abordagem médica à sexualidade enquadra-se na perspectiva higienista da época, considerando o casamento a forma moral e socialmente mais adequada de regular a sexualidade e controlar a disseminação de doenças contagiosas, condenando a prostituição e patologizando a homossexualidade 17. Dos seus trabalhos pioneiros destacam-se a tese de doutoramento em medicina, em 1901, e as provas de concurso para docente da Faculdade de Medicina de Coimbra
(Portugal), em 1902, reunidas na sua obra A Vida Sexual (Fisiologia e Patologia), editada em 1913, e muito buscada. Porém, o acesso a essa obra, durante a ditadura de António Salazar (1932-1968), só podia ser feito com receita médica 18 .

Desse modo, somente após a Revolução de 25 de abril de 1974 começam a ser criadas as condições para o desenvolvimento da sexologia. Assim, após esse primeiro marco de uma "protossexologia”, utilizando o termo de Béjin ${ }^{8}$, a sexologia portuguesa contemporânea emergiu apenas nos anos 1970/1980, quando nos Estados Unidos tinha iniciado no final dos anos 1940.

\section{Anos 1970: os anos do planejamento familiar}

Na década de 60 do século XX, a sociedade portuguesa encontrava-se em plena ditadura Salazarista, a que se associava um quadro de 


\section{Data}

\section{0-1989}

1990-1999

\section{Sexologia no mundo}

Lançamento do DSM-III: aparecimento da categoria diagnóstica "disfunções psicossexuais", em 1980;

Ronald Virag descobre os efeitos da papaverina em injeção intracavernosa no tratamento da ereção: nova era na andrologia farmacológica, em 1982; Fundação da International Society for Impotence Research, em 1982;

Formação em sexologia na Dinamarca, pela Associação Dinamarquesa de

Sexologia Clínica, desde 1982;

1ㅇ Congresso Mundial de Impotência, organizado por Ronald Virag, em 1984; Fundação da Sociedade Brasileira de Estudos em Sexualidade Humana, em 1986;

Curso de especialização em sexualidade humana da Universidade Gama Filho, Rio

de Janeiro (Brasil), em 1986;

Fundação da Associação Brasileira para o Estudo da Inadequação Sexual, em 1987;

Fundação da EFS, em 1988;

Formação em sexologia clínica pelo Instituto de Sexologia Clínica de Roma, desde 1988;

É editado o 1o número da revista International Journal of Impotence Research, em 1989.

É editado o 1으 número da revista Sexologies: European Journal of Sexual Health, em 1992;

Mestrado em sexologia da Universidade Gama Filho, Rio de Janeiro (Brasil), de 1994 a 2005;

Formação em medicina sexual, na Alemanha, aprovada pela German Chamber of Physicians, desde 1995; Elaboração da Declaração de Direitos Sexuais da WAS, durante o XIII Congresso

Mundial de Sexologia, em 1997;

Lançamento do Viagra para tratamento oral da disfunção erétil, em 1998: marco do surgimento da "terceira sexologia"; Aprovação da Declaração de Direitos Sexuais da WAS, durante o XIV Congresso Mundial de Sexologia, em 1999.

Sexologia em Portugal

Contexto sociopolítico e cultural

1ํ Congresso Português de Andrologia, e SPA torna-se membro da International Society of Andrology, em 1982;

1ㅇ Congresso Nacional de Sexologia, organizado com a Associação Portuguesa de Terapia do Comportamento, em 1984; Criação da SPSC, em 1985 - Presidente: Francisco Allen Gomes (psiquiatra), Vicepresidentes Afonso de Albuquerque e Júlio Silveira Nunes (psiquiatras);

1ạ edição de Sexologia em Portugal, coordenada pelos psiquiatras Francisco Allen Gomes, Afonso de Albuquerque e Júlio Silveira Nunes, em 1987.

É editado o 1ㅇ número da revista Acta Portuguesa de Sexologia, da SPSC, em 1994;

Eleição da 4ạ Direção da SPSC para 1994-

1996, Fernanda Mendes (psiquiatra) é eleita presidente (1a mulher);

Inicia a pós-graduação em sexologia clínica da SPSC, com atribuição de título de terapeuta sexual, em 1995;

Criação da Sexualidade em Linha parceria entre APF e Instituto Português da Juventude, em 1998;

Inicia o mestrado transdisciplinar de sexologia da Universidade Lusófona, em 1998.
* Identificação do HIV, em 1981; ** Revisão do Código Penal Potuguês que descriminaliza a homossexualidade, em 1982;

** Primeiro caso identificado de HIV em Portugal, em 1983;

** Lei no 6/84: exclusão de ilicitude em alguns casos de interrupção voluntária da gravidez em Portugal;

** Lei no 3/84: educação sexual e planejamento familiar em Portugal;

** Inquérito nacional sobre os conhecimentos, as atitudes e comportamentos face à AIDS, em Portugal, em 1987.
** Iniciam os programas de rádio sobre sexualidade em 1990: Caleidoscópio Sexual, com o psiquiatra Francisco Allen

Gomes e O Sexo dos Anjos, com o

psiquiatra Júlio Machado Vaz;

** Primeiro programa de televisão Sexualidades, na RTP, televisão estatal, com Júlio Machado Vaz, em 1991/1992;

* Conferência de consenso sobre impotência sexual, nos Estados Unidos, em 1992: marco da medicalização da impotência;

** Início das atividades da ILGA-Portugal, em 1995;

** Realização do 1ㅇ Inquérito à Fecundidade e Família pelo INE, em Portugal, em 1997;

** Primeira cirurgia de reatribuição de sexo, em Portugal, em 1998;

** 1 으 referendo do aborto, em 1998: a despenalização não foi garantida;

** Inicia em Portugal o programa semanal

na rádio nacional Antena 3, A Hora do

Sexo, com o psicólogo Quintino Aires, em 1998, ainda em emissão.

(continua) 


\section{Data}

$2000-2009$

Sexologia no mundo

Elaboração do documento Promotion of Sexual Health: Recommendations for Action pela OPAS e OMS: difusão da noção de direitos sexuais, em 2000; Lançamento do Cialis e Levitra para o tratamento oral da disfunção erétil, em 2003;

A WAS torna-se World Association for Sexual Health, com a mesma sigla, em 2003;

A International Society for Impotence Research torna-se International Society for Sexual Medicine (ISSM), em 2004; EFS estabelece colaboração com a European Society of Sexual Medicine (ESSM): The European Academy for Sexual Medicine (EASM), em 2004; Mestrado em sexologia, na Suécia, pela Universidade de Ciências Aplicadas, em 2007.

2010-2014

Criação da Training and Education Committee pela EFS, para a cooperação entre as diferentes entidades responsáveis pela formação em sexologia na Europa, em 2010;

Primeira certificação em sexologia clínica pela EFS e ESSM, em 2014;

Lançamento do DSM-V: nova classificação das disfunções sexuais, em 2013.
Criação do ILASC, em 2010;

Realização do 10ำ Congresso da EFS em Portugal, no Porto, pelos 25 anos da SPSC, em 2010;

Inicia a pós-graduação em sexologia clínica pelo Instituto CRIAP - Psicologia e Formação Avançada, no Porto, em 2010; Realização do 38 Congresso da IASR em Portugal, no Estoril, sob a organização da SPSC, em 2012.
Contexto sociopolítico e cultural

** 1ạ Marcha do Orgulho LGBT, em Lisboa, pela ILGA, em 2000;

** Lei no 12/2001 autoriza a venda livre da pílula do dia seguinte nas farmácias e o seu fornecimento nos centros de atendimento de jovens, em Portugal;

** Uniões de Fato são estendidas a casais de pessoas do mesmo sexo, em Portugal, em 2001;

** Revisão da Constituição Portuguesa com o artigo 13o que inclui a orientação sexual como fator de não-discriminação, em 2004: Portugal é o $1^{\circ}$ país europeu e 4ㅇ mundial a referir a orientação sexual na constituição:

** Em 2005 e 2006, programa televisivo AB Sexo, na televisão privada TVI, apresentado pela psicóloga Marta Crawford;

** A Comissão para Igualdade e para os

Direitos das Mulheres passa a Comissão para a Cidadania e Igualdade de Género, em 2007;

** Revisão do Código Penal Português introduz violência doméstica enquanto crime público, em 2007;

** Lei no 60/2009: educação sexual em meio escolar em Portugal;

** Em 2009, programa televisivo Aqui Há Sexo, na TVI24, apresentado pela psicóloga Marta Crawford;

** Em 2009, programa de rádio Sexo à Janela no Éter, no Rádio Clube Português, apresentado pela psicóloga Patrícia Pascoal.

** Alteração da lei do casamento com a inclusão de pessoas do mesmo sexo, com exceção da adoção, em 2010;

** Lei da Identidade de Gênero: procedimento de mudança de sexo e de nome próprio no registo civil, em Portugal, em 2011;

** Desde 2012, programa televisivo 100

Tabus na SIC Mulher, apresentado pela psicóloga Marta Crawford;

** Desde 2014, programa televisivo Tanto Para Conversar, entrevistas com Gabriela Moita, psicóloga, às sextas-feiras na RTP2 (canal público).

APF: Associação para o Planeamento da Família; DSM: Manual Diagnóstico e Estatístico de Transtornos Mentais; EFS: Federação Europeia de Sexologia; IASR: International Academy of Sex Research; ILASC: Instituto Luso-Americano de Sexologia Clínica; ILGA: International Lesbian and Gay Association; INE: Instituto Nacional de Estatística; OMS: Organização Mundial da Saúde; OPAS: Organização Pan-Americana da Saúde; SPA: Sociedade Portuguesa de Andrologia; SPSC: Sociedade Portuguesa de Sexologia Clínica; WAS: Associação Mundial de Saúde Sexual.

* Grandes marcos mundiais (adaptação de Russo 11);

** Marcos portugueses. 
pobreza da grande maioria da população. No que diz respeito à saúde materna e infantil, registavam-se elevadas taxas de mortalidade, uma elevada prevalência de aborto clandestino, ausência de quaisquer métodos anticoncepcionais e de serviços de planejamento familiar. A sexualidade era um domínio cujos saberes e regras deviam seguir a restritiva moral da Igreja Católica, apoiada pelo Estado Novo e as suas instâncias de regulação 17,19 .

No contexto das transformações sociais e econômicas ocorridas em nível mundial no contexto do pós-guerra, começou a surgir nos meios universitários portugueses alguma contestação aos constrangimentos do comportamento sexual e da vida social em geral. Um marco simbólico da resistência à desigualdade de gênero vivida na época e do apelo à libertação sexual é a publicação, em 1961, no órgão da Associação Académica da Universidade de Coimbra, Via Latina, da Carta a uma Jovem Portuguesa. A carta é um alerta dirigido a uma jovem imaginária para a sua falta de liberdade amorosa e ao tratamento diferenciado em relação aos rapazes, e ao mesmo tempo uma crítica ao sistema social. O texto, apesar de limitado ao contexto universitário, muito minoritário na época, contribuiu para lançar o debate sobre a condição feminina 20 .

Ao longo dos anos 1960 e início dos anos 1970, emergiu uma consciência crítica e uma ação concertada, nomeadamente entre os chamados católicos progressistas no interior da própria Igreja Católica, com o objetivo de promover mudanças nesse estado de coisas 21 .

Em 1967, a APF, uma ONG, foi fundada por profissionais de saúde, nomeadamente médicos ginecologistas, entre os quais Albino Aroso, Manuel Neves e Castro e Purificação Araújo, e por ativistas católicos, no contexto da polêmica causada pelos debates do Concílio Vaticano II acerca do controle da natalidade e posteriormente pela publicação da encíclica Humanae Vitae. Fruto das dinâmicas introduzidas pela revolução democrática de abril de 1974 na vida cultural e social portuguesa, a APF começou a expandir e diversificar a sua atuação. Além de consultas de planejamento familiar, promoveu atividades de formação. O seu presidente, Albino Aroso, assinou, enquanto Secretário de Estado da Saúde, em 1976, um normativo legal para facilitar o acesso das mulheres ao planejamento familiar nos cuidados primários de saúde 22 .

Enquanto no regime autoritário do Estado Novo, que desde os anos 30 do século XX defendia o rígido tradicionalismo materializado no lema "Deus, Pátria e Família", as liberdades sexuais permitidas aos homens contrastavam com a pureza e contenção exigidas às mulheres; as alterações legislativas do período pós-1974 contribuíram para uma sexualidade desligada do casamento e da estrita função reprodutiva. A Constituição de 1976 reconheceu a igualdade entre homens e mulheres e o Código Civil, que em 1967 declarava que "a falta de virgindade da mulher ao tempo do casamento" constituía fator relevante para a sua anulabilidade legal, foi revisto em 197718 .

Em 1978, foi publicado o primeiro número do boletim Planeamento Familiar da APF, atualmente intitulado Sexualidade \& Planeamento Familiar. Numa publicação de 2008, foi feito um retrato de três décadas da revista e uma análise cronológica dos seus principais temas e conteúdos, mostrando que se os anos 1970 foram dedicados majoritariamente à temática do planejamento familiar, os anos 1980 passaram a ter o enfoque na sexologia. O tema da sexologia surgiu pela primeira vez em dezembro de 1979 num texto intitulado Do Planeamento Familiar à Sexologia 23 .

A principal mudança que se desenhou consistiu na aceitação social de uma sexualidade desligada da reprodução e orientada para o prazer, e nos vários modelos que emergiram para alcançá-la, mais do que a constituição de uma sexualidade mais "emancipada e emancipatória”. O prazer sexual autonomizado da reprodução caiu cada vez mais sob o controle médico e de todo um vasto elenco de atores "disciplinares" da sexualidade, quais sejam os sexólogos, psicanalistas, psicólogos, epidemiologistas, cientistas sociais, assistentes sociais, professores, entre outros 6 .

\section{Anos 1980: o desenvolvimento da sexologia}

Apesar das primeiras consultas de sexologia nos hospitais universitários de Coimbra, Lisboa e Porto datarem de 1975, foi nos anos 1980 que se assistiu à passagem do planejamento familiar para um enfoque na sexologia, com os primeiros estudos a serem implementados e uma variedade de abordagens e temáticas surgirem. Essa diversidade é bem ilustrada na obra de referência Sexologia em Portugal, coordenada por Francisco Allen Gomes, Afonso de Albuquerque e Júlio Silveira Nunes, publicada em 1987. A obra contempla autores de várias especialidades médicas e não-médicas, e temas que vão desde o comportamento sexual humano e os problemas sexuais e o seu tratamento, à sexualidade e história, sexualidade e religião, sexualidade e antropologia, entre outros 24 .

Desse modo, no final dos anos 1970 e durante os anos 1980 foram criadas instituições e realizados eventos científicos ligados à sexologia. 
Em 1979, realizou-se o primeiro congresso de andrologia em Lisboa e foi fundada a Sociedade Portuguesa de Andrologia (SPA), que se dedica ao estudo da função sexual masculina com um particular enfoque no distúrbio androgênico do envelhecimento masculino ou "andropausa". O primeiro Congresso Nacional de Sexologia foi realizado em Lisboa em 1984, com o objetivo de agrupar os profissionais das várias áreas da sexologia, nomeadamente médicos, psicólogos, educadores e sociólogos, e em 1985 foi criada a SPSC. A criação da SPSC veio legitimar o papel da sexologia como ciência da sexualidade em Portugal e o papel do sexólogo como especialista com competências para intervir nesta área, à semelhança do que se passava no contexto internacional.

\section{Anos 1980-1990: os anos do HIV/AIDS}

A expansão da investigação em sexologia está também intimamente ligada à emergência do HIV e AIDS. O primeiro caso clínico de infeção pelo HIV em Portugal foi diagnosticado em 1983. Em 1985, foi criado o Grupo de Trabalho sobre AIDS pelo Ministério da Saúde. A partir do final dos anos 1980 foram desenvolvidas, em nível nacional e à semelhança do contexto internacional 25 , pesquisas dedicadas às doenças transmissíveis 26,27 e emergiram alguns movimentos sociais de combate à estigmatização da doença, como resposta a um discurso do risco associado à sexualidade, um discurso também moralista $\mathrm{e}$ moralizador, em torno da associação entre comportamentos desviantes e HIV/AIDS. A epidemia veio questionar as certezas que então vigoravam sobre o irreversível progresso da medicina em relação às doenças infectocontagiosas, originando um movimento de reflexão e pesquisa, e novas parcerias entre atores sociais (investigadores médicos e ativistas, órgãos de saúde e organizações comunitárias etc.) 28 .

Segundo Miguel Vale de Almeida 29, a AIDS apareceu como a doença "impura" e dos "impuros”, uma espécie de vingança da natureza ou dos deuses contra a liberalização dos costumes nas décadas de 1960 e 1970, e especialmente contra os que mais punham em causa o modelo reprodutivo - os homossexuais.

A emergência do HIV/AIDS teve um papel chave no despertar do associativismo lésbico, gay, bissexual e transgênero (LGBT) em Portugal. Foi o contexto de combate à AIDS que impulsionou o movimento associativo, que até então viveu uma história de opressão, negação e controle social 30 .

Em 1995, a International Lesbian and Gay Association (ILGA-Portugal) iniciou as suas atividades e tornou-se a maior associação portuguesa de defesa dos direitos LGBT, quer pelo número de sócios quer pelas iniciativas, das quais se destacam o Arraial do Orgulho Gay, considerado o maior acontecimento LGBT de Portugal, e o Festival de Cinema Gay e Lésbico 31. Os anos 1990 ficaram marcados por um contexto de lutas e pela emergência de novos conceitos de cidadania sexual. A inclusão da sociedade civil em questões relacionadas com a AIDS, para além de fomentar a capacidade de participação dos cidadãos, introduziu a esfera privada da sexualidade no domínio do debate público, contribuindo para uma desmistificação do sexo e de tudo o que está associado a ele 31 .

O primeiro programa de televisão sobre sexualidade (Sexualidades) data do início dos anos 1990 e passou no canal público português RTP, com o psiquiatra Júlio Machado Vaz, que já tinha iniciado a discussão deste tema na rádio (Sexo dos Anjos). Mas foi na década seguinte, e já num contexto de privatização da televisão portuguesa, que os programas televisivos multiplicaram ( $A B$ Sexo, na TVI em 2005; Aqui Há Sexo, na TVI24 em 2009; e 100 Tabus, na SIC Mulher desde 2012, com a psicóloga Marta Crawford, são exemplos).

Anos 2000: os anos da farmacologização da sexualidade e dos movimentos sociais

No cruzamento dos campos político e da sexualidade, destacam-se os discursos em torno dos direitos sexuais e reprodutivos. Os debates acerca da despenalização do aborto e os dois referendos sobre a interrupção voluntária da gravidez (IVG), em 1998 e 2007, são exemplos de como a sexualidade é um campo de lutas morais e políticas. Em 1998, o "não" à despenalização ganhou com 51\% dos votos expressos (apenas 32\% do eleitorado foram às urnas). Em 2007, o "sim" ganhou com $59 \%$, mas o comparecimento às urnas (46\%) foi insuficiente para tornar o referendo vinculativo. Porém, o Parlamento aprovou a descriminalização da prática da IVG até as 10 semanas da gravidez se esta resultar de uma opção da mulher (Lei no 16/2007).

Os debates em torno da IVG estão também associados à intervenção das autoridades públicas em matéria de educação sexual em meio escolar, entre 1984 e 2009 (data da primeira e última legislação aprovada na Assembleia da República). As políticas em torno dessas temáticas têm sido palco de lutas pela definição dos limites do íntimo e do público, do comunitário e do societário, e da intervenção da autoridade pública, bem como pela verdade científica disputada pelos saberes profissionais e os saberes que dependem do juízo ético. As políticas de educação sexual em meio escolar foram marcadas pela intervenção 
de ONGs nacionais, nomeadamente da APF, que participaram na produção legislativa, criação de programas, redes e grupos de trabalho 32 .

Os movimentos de luta pelo casamento entre pessoas do mesmo sexo constituem outro exemplo do processo de alargamento dos direitos sociais na vida privada. A união de fato entre pessoas do mesmo sexo foi reconhecida em Portugal em 2001 e o casamento em 2010. Apesar do reconhecimento de vários direitos iguais, permanecem os limites da possibilidade de adoção e do direito à procriação medicamente assistida. $\mathrm{O}$ acesso às técnicas de procriação medicamente assistida (em 2006 foi instituído o Conselho Nacional de Procriação Medicamente Assistida), como a inseminação artificial ou a fertilização em vitro, está impedido a mulheres sós, casais do mesmo sexo e indivíduos transgênero, reforçando as ideias dominantes acerca da feminilidade e da família 33.

Para além dessa dimensão política da sexualidade, verifica-se um intensificar do desenvolvimento do campo nas intervenções médicas e psicológicas sobre a sexualidade. Em 2010, coube à SPSC, nos seus 25 anos, a organização do 10o Congresso da European Federation of Sexology na cidade do Porto. Foi discutido o estado da arte da investigação da sexologia nacional (mais de 200 trabalhos de autores portugueses), tendo sido dedicada uma edição especial à pesquisa sexológica em Portugal na revista Sexologies (revista oficial da European Federation of Sexology) em 2011 34. Os eventos científicos, nacionais e internacionais, fazem parte de um trabalho de reprodução das relações estabelecidas no campo, ao qual os médicos, com o patrocínio da indústria farmacêutica, têm maior acesso. Os primeiros anos do século XXI ficam marcados pela crescente medicalização/farmacologização da sexualidade e pela investigação sobre sexualidade e função sexual, um mercado cada vez mais lucrativo. A medicina sexual assumiu cada vez mais importância na sexologia portuguesa, nomeadamente desde 1998, com a comercialização do sildenafil. Em 2013, foram vendidas 568.577 embalagens de medicamentos para a disfunção erétil e faturados 22.438.570 Euros 35 .

\section{Protagonistas e fases da profissionaliza- ção da sexologia em Portugal}

\section{A primeira sexologia: dois grupos de atores e dois caminhos}

A primeira fase da sexologia contemporânea portuguesa (1967-1998) foi caracterizada por ter dois grupos de atores e dois caminhos distintos, um em torno da ginecologia e outro em torno da psiquiatria.

Albino Aroso, considerado o "pai do planejamento familiar", além de fundador da APF, foi responsável pela implementação da primeira consulta pública e gratuita de planejamento familiar, em 1969. O seu trabalho esteve na base da legislação que foi determinante para alterar o panorama da saúde materna e infantil em Portugal, e foi também militante pela causa da educação sexual. A pílula anticoncepcional, que desde 1962 era comercializada nas farmácias como método de regulação do ciclo menstrual, não existia no Serviço Nacional de Saúde e era usada somente por uma minoria de mulheres portuguesas de classes sociais médias. Foi somente a partir de agosto de 1974 que a pílula passou a ser autorizada como anticoncepcional pela autoridade nacional do medicamento. Assim, inicialmente o planejamento familiar foi o mecanismo de luta contra o fenômeno do aborto clandestino, que funcionava como um meio corrente de controle da natalidade com graves consequências na saúde materna. A APF marcou a fase emergente da saúde sexual e reprodutiva em Portugal, e ficou até a atualidade como uma das associações de referência nesta área, desempenhando um papel ativo no desenvolvimento e implementação das políticas de saúde sexual e reprodutiva 36 .

Desse modo, parece existir uma forte ligação inicial da ginecologia com o planejamento familiar e a saúde sexual e reprodutiva, à semelhança da sexologia brasileira, que em meados dos anos 1960 tinha um grupo de discussão sobre os problemas ligados à ginecologia designado Clube da Placenta ${ }^{13}$. Na atualidade, e com a afirmação crescente dos direitos sexuais e de uma sexualidade voltada para o prazer, existem na sexologia portuguesa alguns profissionais da ginecologia dedicados ao estudo do funcionamento e satisfação sexual. Mas esses são em número pouco expressivo e a ginecologia deixou de ser a especialidade médica a garantir a legitimação científica e profissional da sexologia.

O segundo grupo de atores é constituído por Afonso de Albuquerque, Francisco Allen Gomes, António Palha, Silveira Nunes e Júlio Machado Vaz, os cinco psiquiatras mais conhecidos da sexologia portuguesa. Eles trouxeram para Portugal a sexologia de Masters e Johnson, que aprenderam em estágios realizados no estrangeiro. Aplicaram-na primeiramente nas consultas de sexologia que criaram em meados dos anos 1970 e, posteriormente, com o afrouxar dos constrangimentos políticos, de uma forma mais ampla e institucionalizada, com a realização de encontros científicos, no associativismo (a criação da 
SPSC em 1985) e depois no ensino (a criação da pós-graduação em sexologia clínica em 1995). Existe uma proximidade da psiquiatria com as terapias comportamentais e a sua extensão à sexologia, a partir de 1970. A terapia comportamental está presente nos percursos desses cinco psiquiatras, que são tidos como os pioneiros da sexologia portuguesa e que promovem uma visão holística da sexualidade nas suas áreas específicas de interesse, nomeadamente estudos sobre homossexualidade, disfunções sexuais e transsexualismo.

A maior parte desses psiquiatras pioneiros continua a ser figuras de destaque no campo da sexologia, estando nomeadamente ligados ao ensino pós-graduado nesta área. No entanto, a psiquiatria parece ter perdido o papel principal no campo. Com o domínio da medicina sexual e o centramento no funcionamento da sexualidade, preferencialmente masculina, a psiquiatria enfrenta uma maior dificuldade de constituição de uma "clientela", que passa a ser disputada com a urologia, a endocrinologia e, por fim, com a psicologia. Com efeito, tal como na sexologia brasileira, os psicólogos disputam com os psiquiatras a terapia comportamental 13 .

Um terceiro núcleo de profissionais que só mais tarde assumirá protagonismo no campo, mas que inicia a sua atividade nesta primeira fase, especificamente com a criação da SPA, são os andrologistas. Em Portugal, grupos de trabalho foram formados em Lisboa, Coimbra e Porto compostos sobretudo por urologistas, como Adriano Pimenta, tido como o "pai da andrologia portuguesa”, António Requixa e Jorge Rocha Mendes, e endocrinologistas, entre os quais $\mathrm{Al}-$ berto Galvão-Teles, primeiro diretor da SPA.

Anteriormente à medicação para a disfunção erétil, implementava-se a terapia de reposição hormonal no contexto da difusão de novos diagnósticos como a andropausa (para classificar uma diminuição progressiva da produção de testosterona em homens após os 50 anos), e de uma medicalização da velhice com uma redefinição do envelhecimento e um "reempoderamento masculino" 5.

Em 1998, os andrologistas colocaram o Viagra, ou "pílula da felicidade", no centro do tratamento da disfunção erétil, adotando a abordagem da saúde sexual preconizada pela Organização Mundial da Saúde (OMS) 37.

Enquanto a fase do nascimento da sexologia em Portugal foi dominada pelos psiquiatras, ginecologistas e andrologistas, nessa fase de transição da sexologia, Portugal representou um modelo mais próximo do brasileiro, com os andrologistas como figuras de destaque, do que do europeu, nomeadamente o caso francês com ginecologistas, psiquiatras e médicos de clínica geral, e do de países escandinavos e Itália, com psicólogos, enfermeiros e parteiras ${ }^{9}$.

\section{A segunda sexologia: dois atores e} um caminho

A segunda geração da sexologia portuguesa é contemporânea da terceira fase da sexologia internacional, ou seja, da "medicalização" da sexualidade, e caracteriza-se por ter dois grupos de atores principais, os urologistas e os psicólogos, mas um caminho principal, focado no indivíduo e na fisiologia sexual.

Esse período fica também marcado pela afirmação da sexologia como ciência da sexualidade e os primeiros passos para a legitimação acadêmica. Em 1995, começou a Pós-graduação em Sexologia Clínica da SPSC. Essa formação é a única em Portugal a conferir um título de terapeuta sexual para aqueles que finalizam os dois anos de treinamento do programa, com sessões de supervisões, pesquisa e prática clínica. O Mestrado Transdisciplinar de Sexologia da Lusófona, uma universidade privada em Lisboa, coordenado pelo urologista Nuno Monteiro Pereira, data de 1998, e o seu programa de estudos divide-se em três ramos: Psicologia da Sexualidade; Sexualidade Humana; e Medicina Sexual. Essas formações são responsáveis por um aumento da investigação na área da sexualidade. Porém, sem uma oferta acadêmica mais ampla, nomeadamente a existência de licenciaturas e doutoramentos em sexologia, a institucionalização e legitimidade acadêmica da sexologia permanece incompleta. Com efeito, a maioria das especializações em sexologia permanece extrauniversitária ou nas margens das especialidades e instituições de maior prestígio no meio profissional e acadêmico, e a sexologia não se converteu num território universitário específico.

Em 2003, 16 anos após o primeiro manual de sexologia em Portugal e na mesma linha de multidisciplinaridade, foi editada a obra $A$ Sexologia, com a coordenação da presidente e vice-presidentes da SPSC, as psicólogas Lígia Fonseca e Catarina Soares e o psiquiatra Júlio Machado Vaz 38 . A abordagem da sexualidade diversificou-se para além das suas principais áreas (funcionamento sexual, educação sexual, e direitos e saúde sexual e reprodutiva), passando a discutir temas como a violência doméstica, o ciber sexo, entre outros.

Em 2009, abriu em Portugal o primeiro laboratório dedicado à investigação experimental e psicofisiológica da sexualidade humana (SexLab), constituído por uma equipe de psicólogos dirigida por Pedro Nobre, o que assinalou uma mudança na investigação em sexologia 
no país. A partir daquele momento a psicologia assumiu um papel indiscutível de destaque na sexologia portuguesa e obteve reconhecimento internacional, sendo a proliferação das publicações científicas de psicólogos portugueses, na sua maioria do SexLab, em revistas de sexologia internacionais um indicador desta expansão e reconhecimento.

Analisar a sexologia como um campo permite identificar conflitos e consensos, e também estratégias de restrição ou ampliação dos limites ao exercício da profissão ou ocupação, isto é, de quem pode ou não fazer parte do campo. Como vimos, a SPSC é a única entidade habilitada a acreditar Terapeutas Sexuais em Portugal reconhecidos pela Associação Mundial de Saúde Sexual (WAS) e pela Federação Europeia de Sexologia (EFS), acreditação disponível apenas para médicos e psicólogos com prática clínica. Não obstante, a profissão está insuficientemente institucionalizada em termos de controle e monopólio do título, e alguns profissionais prescindem do mesmo, dado que o título de psicólogo, e mais ainda o de médico, é fonte mais do que suficiente de legitimidade, em Portugal tal como noutros países 9,13. Por fim, verificam-se movimentos de aliança e luta pela hegemonia do campo entre as diferentes profissões e especialidades médicas envolvidas: ginecologistas, psiquiatras, andrologistas, urologistas e psicólogos.

\section{Colaboradores}

V. N. Alarcão contribuiu com o desenho do estudo, coleta e análise dos dados; esboço, redação e revisão crítica do manuscrito; aprovação da versão final a ser publicada; acordo relativo a todos os aspectos do trabalho, assegurando a sua exatidão e integridade. F. L. Machado e A. Giami contribuíram com a revisão crítica do manuscrito, aprovação da versão final a ser publicada, acordo relativo a todos os aspectos do trabalho, assegurando a sua exatidão e integridade.

\section{Conclusão}

Este artigo buscou analisar a sexologia portuguesa como um campo multiprofissional de forças, identificando as principais instituições, atores e práticas profissionais, ao mesmo tempo em que discutia as especificidades do seu processo de institucionalização à luz de um contexto internacional mais global, incluindo o exemplo brasileiro. Visou por isso a contribuir para a compreensão da sexologia enquanto campo científico e profissional, evidenciando que a ciência da sexualidade, tal como qualquer outro domínio científico, é um palco de lutas de classificação social e de disputas pelo monopólio da definição legítima de realidade.

Em Portugal, tal como na América Latina 39, os resultados indicam que os primeiros períodos da emergência e estruturação da sexologia foram pautados, sobretudo, por especificidades de âmbito nacional, associadas ao contexto cultural de cada país, como a presença do planejamento familiar, a influência da religião católica, e o interesse pelo tema de algumas profissões como a ginecologia, a psiquiatria ou a psicologia. Por oposição, a fase mais recente da sexologia é marcada pela medicalização e farmacologização da sexualidade, verificando-se um movimento de homogeneização da medicina sexual centrada no tratamento de disfunções sexuais. No entanto, observa-se também a presença da perspectiva da saúde sexual, baseada em aproximações psicossociais e educacionais, com enfoque nos direitos sexuais e com o apoio de organizações de direitos humanos.

\section{Agradecimentos}

Os autores são gratos às três associações nacionais, Sociedade Portuguesa de Sexologia, Sociedade Portuguesa de Andrologia, Associação para o Planeamento da Família; e ao Mestrado Transdisciplinar de Sexologia da Universidade Lusófona na pessoa do Professor Nuno Monteiro Pereira, pela colaboração na implementação do estudo. Os autores agradecem à equipe de pesquisa, nomeadamente ao Professor Alberto Galvão-Teles, e Ana Beato, Joana Almeida e Madalena Cunha pela colaboração na coleta de dados. 


\section{Referências}

1. Foucault M. História da sexualidade I. A vontade de saber. Lisboa: Relógio d'Água; 1994.

2. Giami A. A medicalização da sexualidade. Foucault e Lantéri-Laura: história da medicina ou história da sexualidade? Physis (Rio J.) 2005; 15:259-84.

3. Tiefer L. The medicalization of sexuality: conceptual, normative, and professional issues. Annu Rev Sex Res 1996; 7:252-82.

4. Irvine JM. Disorders of desire: sexuality and gender in modern American sexology. Philadelphia: Temple University Press; 2005.

5. Russo J. A terceira onda sexológica: medicina sexual e farmacologização da sexualidade. Sex Salud Soc (Rio J.) 2013; 14:172-94.

6. Loyola MA. Sexualidade e medicina: a revolução do século XX. Cad Saúde Pública 2003; 19:875-84.

7. Béjin A. O poder dos sexólogos e a democracia sexual. In: Ariès P, Béjin A, organizadores. Sexualidades ocidentais. São Paulo: Brasiliense; 1987. p. 236-54.

8. Béjin A. Crepúsculo dos psicanalistas, manhã dos sexólogos. In: Ariès P, Béjin A, organizadores. Sexualidades ocidentais. São Paulo: Brasiliense; 1987. p. 210-35.

9. Giami A. The social and professional diversity of sexology and sex-therapy in Europe. In: Hall $\mathrm{K}$, Graham C, editors. Cultural context of sexual pleasure and problems: psychotherapy with diverse clients. London: Routledge; 2012. p. 375-93.

10. Bourdieu P. Esboço de uma teoria da prática. Oeiras: Celta Editora; 2002.

11. Russo J. Sexualidade, ciência e profissão no Brasil. Rio de Janeiro: Centro de Estudos e Pesquisa em Saúde Coletiva; 2011.

12. Giami A. Cent ans d'hétérosexualité. Actes Rech Sci Soc 1999; 128:38-45.

13. Russo J, Rohden F, Torres I, Faro L. O campo da sexologia no Brasil: constituição e institucionalização. Physis (Rio J.) 2009; 19:617-36.

14. Carrara S. Tributo a Vênus: a luta contra a sífilis no Brasil, da passagem do século aos anos 40. Rio de Janeiro: Editora Fiocruz; 1996.

15. Giami A. De l'impuissance à la dysfonction érectile. Destins de la médicalisation de la sexualité. In: Fassin D, Memmi D, editors. Le gouvernement des corps. Paris: Editions EHESS; 2004. p. 77-108.

16. Brandão AM. Da sodomita à lésbica: o género nas representações do homo-erotismo feminino. Anal Soc 2010; 195:307-27.

17. Policarpo V. Sexualidades em construção: entre o público e o privado. In: Nunes de Almeida A, organizador. História da vida privada em Portugal. Lisboa: Círculo de Leitores; 2011. p. 48-79.

18. Aboim S. A sexualidade dos portugueses. Lisboa: Fundação Francisco Manuel dos Santos; 2013.

19. Freire I. Amor e sexo no tempo de Salazar. Lisboa: A Esfera dos Livros; 2010.

20. Bebiano R, Silva A. A reidentificação do feminino e a polémica sobre a 'Carta a uma Jovem Portuguesa'. Revista História das Ideias 2004; 25:423-54.

21. Monteiro T. Fés, credos e religiões. In: Nunes de Almeida A, organizador. História da vida privada em Portugal. Lisboa: Círculo de Leitores; 2011. p. 278-307.
22. Rebelo DM. O movimento do planeamento familiar. In: Gomes FA, Albuquerque A, Nunes JS, organizadores. Sexologia em Portugal. Lisboa: Texto Editora; 1987. p. 103-7.

23. Inácio A, Guerreiro E. 30 anos de história. Revista Sexualidade \& Planeamento Familiar (19782008). Sexualidade \& Planeamento Familiar 2008; 50/51:6-15.

24. Gomes FA, Albuquerque A, Nunes JS, organizadores. Sexologia em Portugal. Lisboa: Texto Editora; 1987.

25. Parker R. Unintended consequences: evaluating the impact of HIV and AIDS on sexuality research and policy debates. Cad Saúde Pública 2009; 25 Suppl 2:S251-8.

26. Lucas JS. Os portugueses e a SIDA: inquérito nacional sobre conhecimentos, atitudes e comportamentos associados com a SIDA. Rev Port Saúde Pública 1987; 5:98-100.

27. Amaro F, Dantas AM, Cunha Teles L. Sexual behaviour in the city of Lisbon. Int J STD AIDS 1995; 6:35-41.

28. Bastos C. A pesquisa médica, a SIDA e as clivagens da ordem mundial: uma proposta de antropologia da ciência. Anal Soc 1997; 140:75-111.

29. Almeida MV. Sida: a doença impura. Planeamento Familiar 1992; 58-59:18-9.

30. Cascais AF. Diferentes como só nós: o associativismo GLBT português em três andamentos. Revista Crítica de Ciências Sociais 2006; 76:109-26.

31. Santos AC. Sexualidades politizadas: ativismo nas áreas da AIDS e da orientação sexual em Portugal. Cad Saúde Pública 2002; 18:595-611.

32. Carvalho L, Figueiredo C. Configurações de conhecimento e política na regulação da educação sexual em meio escolar. Educação, Sociedade \& Culturas 2012; 34:67-88.

33. Machado T, Brandão A. Regulating lesbian motherhood: gender, sexuality and medically assisted reproduction in Portugal. Laws 2013; 2:469-82.

34. Nobre P. Editorial. Sexologies 2011; 20:205-6.

35. Centro de Estudos e Avaliação em Saúde, Associação Nacional das Farmácias. Medicamentos usados na disfunção eréctil. Lisboa: Centro de Estudos e Avaliação em Saúde, Associação Nacional das Farmácias; 2013.

36. Vilar D. Contributos para a história das políticas de saúde sexual e reprodutiva em Portugal. e-cadernos CES 2009; (04). http:// eces.revues.org/203.

37. Giami A. Sexual health: the emergence, development, and diversity of a concept. Annu Rev Sex Res 2002; 13:1-35.

38. Fonseca L, Soares C, Vaz JC. A sexologia: perspectiva multidisciplinar I e II. Coimbra: Quarteto Editora; 2003.

39. Giami A, Russo J. The diversity of sexologies in Latin America: emergence, development, and diversification. Int J Sex Health 2013; 25:1-12. 


\section{Abstract}

Based on Bourdieu's field theory, this article analyzes the emergence and institutionalization of sexology as a science and profession in Portugal, identifying relevant institutions, actors, and professional practices and discussing its relations and specificities. The analysis begins by contextualizing the emergence of modern Western sexology in order to comprehend the Portuguese case in the international sexology context. The second section describes the social, cultural, and institutional factors that have driven the professionalization of sexology. The third section describes the emergence of Portuguese sexology and its principal historical milestones, institutions, and actors. Finally, the article discusses some implications of this process for the role of sexology as a science and profession. The study reveals the dynamics of national and international processes in the field, in the transition from a holistic perspective of sexology to the hegemony of sexual medicine, and sheds light on its mechanisms of legitimation as a transdisciplinary science of sexuality, suggesting future perspectives.

Sexology; Scientific Domains; Sexual and

Reproductive Health; Reproductive Health Services

\section{Resumen}

En base a la teoría de los campos de Bourdieu, este artículo analiza la emergencia y la institucionalización de la sexología como ciencia y profesión en Portugal identificando instituciones, actores y prácticas profesionales, y discutiendo sus relaciones y especificidades. Comienza por contextualizar el surgimiento de la sexología moderna occidental para una comprensión del caso portugués en el contexto sexológico internacional. En una segunda parte, se describen los factores de naturaleza social, cultural e institucional que han impulsado la profesionalización de la sexología. En la tercera parte, se describe la emergencia de la sexología portuguesa y sus principales marcos históricos, instituciones, y actores en juego. Finalmente, discute algunas implicaciones de este proceso para el papel de la sexología como ciencia y profesión. Esta investigación revela las dinámicas entre procesos nacionales e internacionales en el campo, en la transición de una perspectiva holística de la sexología para la hegemonía de la medicina sexual, y clarifica sus mecanismos de legitimización como ciencia transdisciplinaria de la sexualidad, sugiriendo perspectivas futuras.

Sexología; Dominios Científicos; Servicios de Salud Reproductiva; Salud Sexual y Reproductiva
Recebido em 08/Mar/2015

Versão final reapresentada em 21/Out/2015 Aprovado em 22/Fev/2016 